Revista aSEPHallus de Orientação Lacaniana

Núcleo Sephora de Pesquisa sobre o Moderno e o Contemporâneo

ISSN $1809-709 \mathrm{X}$

\title{
Memórias de uma experiencia amarga: a pandemia de COVID-19
}

Tania Coelho dos Santos

Orcid: https://orcid.org/0000-0002-5360-7864

Pós-doutorado no Departamento de Psicanálise de Paris VIII (Paris, França)

Professor Associado, nível IV no Programa de Pós-graduação em Teoria Psicanalítica/UFRJ (Rio de Janeiro, Brasil) Pesquisadora Bolsista de Produtividade Científica do CNPQ nível $1 \mathrm{C}$

Presidente do Instituto Sephora de Ensino e Pesquisa de Orientação Lacaniana/ ISEPOL (Rio de Janeiro, Brasil) Psicanalista Membro da École de La Cause Freudienne, da Escola Brasileira de Psicanálise e da Associação Mundial de Psicanálise Membro da Associação Universitária de Pesquisa em Psicopatologia Fundamental (Rio de Janeiro, Brasil) E-mail: taniacs@openlink.com.br

A pandemia ainda está bem longe de ter sido controlada. Precisamos falar dela e testemunhar, refletir e avaliar a experiência amarga que ela nos impôs. Nos jornais não se fala de outra coisa, somente da vacina. Assunto que suscita controvérsias. Alguns a esperam ansiosamente. Confiam que voltarão em breve à vida normal protegidos por ela. Outros rejeitam tomá-la. Consideram que seus benefícios são insuficientes ou que podem causar danos inusitados. O RNA do vírus, base da vacina chinesa pode nos transformar em jacarés, fazer nascer chifres, pelos ou causar deformidades ainda piores.

Endereçamos ao colega Antônio Teixeira em nome de todo o Corpo Editorial de aSEPHallus Revista de Orientação Lacaniana, o pedido de que ele compartilhasse conosco suas reflexões acerca do impacto da pandemia do novo Coronavírus na biopolítica no Brasil e no mundo. Antonio é conhecido é conhecido pelo hábito de comentar as diferentes modalidades do mal-estar na cultura. Seu livro intitulado "A soberania do inútil" reúne artigos que abordam diversos ângulos do problema. Preparamos algumas perguntas, em particular, à respeito da biopolítica na pandemia. É possível comparar os efeitos de uma tragédia de proporções gigantescas como essa pandemia que vivemos com o episódio de 11 de setembro? Muitas pessoas sentiram-se revivendo alguma coisa dessa ordem, especialmente, pelos efeitos que vão reverberar no comportamento dos povos e dos governos.

Para os profissionais de saúde, esse é o caso de Ana Paula Santos, as marcas físicas e psicológicas que essas doenças deixaram atravessam fronteiras e continentes, mas são experiências individuais. Ignorância, ansiedade, angústia, impotência, tristeza, raiva, decepção, medo, empatia, foram narrados nos jornais mesclando dados científicos e momentos vividos. Também Mariana Medrado Dias, Tania Coelho dos Santos, Manuella Itapary R. Moreira e Amanda Buhler Riccieri produziram uma narrativa acerca das "Reações emocionais frente à Pandemia Covid-19. Neste artigo 
elas relatam os depoimentos obtidos através de atendimentos aos colaboradores em situação de urgência subjetiva. $O$ artigo foi construído com base nas experiências da pesquisa em psicanálise aplicada na assistência aos colaboradores de uma instituição hospitalar. Consiste numa abordagem dos impasses psíquicos de funcionários e dos consequentes fenômenos clínico-institucionais encontrados. A atenção psicológica aos colaboradores recebeu maior destaque durante a pandemia Covid-19. Em resposta ao medo do desamparo e à ameaça de morte emergiram reações emocionais intensas e comportamentos disruptivos no ambiente de trabalho. Como consequência, o serviço de psicologia do Hospital Samaritano organizou-se para tratar das urgências subjetivas deflagradas no âmbito institucional.

Da pesquisa em psicanálise aplicada com colaboradores resultou também o artigo intitulado "Help line: relato de experiência sobre um dispositivo de acolhimento aos profissionais de saúde durante a pandemia covid-19". As autoras, Tania Coelho dos Santos, Fernanda Saboya Almendra e Manuella Itapary Ribeiro Moreira narram os efeitos psicológicos do aumento súbito e do crescimento imprevisível da demanda por serviços médico-hospitalares na Rede D’Or. O reconhecimento da sobrecarga emocional e de trabalho da equipe multidisciplinar exigiu do serviço de psicologia novas estratégias de atenção à saúde mental dos funcionários. Por meio de uma linha telefônica, foi possível prestar atendimento psicológico aos colaboradores em urgência subjetiva, pois a crise na saúde da população em geral repercutiu diretamente na saúde física e mental dos profissionais que trabalham nos hospitais.

Rosa Guedes Lopes e Rosilene Ribeiro trazem suas "Observações sobre a relação entre o dinheiro e o capital libidinal em atendimentos de urgência". As autoras registram alguns resultados da pesquisa realizada durante o atendimento a dois pacientes no Projeto de Atendimento Temporário de Psicoterapia de Urgência, oferecido por uma universidade privada. Tratam inicialmente do aumento das manifestações psíquicas patológicas resultantes da urgência subjetiva produzida pela pandemia da Covid-19 como ameaça à manutenção da vida. Destacam os principais pontos da obra freudiana acerca da organização anal da libido e das fezes como objeto de satisfação pulsional e sua relação com o valor do dinheiro. Acrescentam que a relação de cada sujeito com o dinheiro pode se apresentar na transferência como exigência de satisfação pulsional autoerótica. A repetição indica o lugar do sujeito e do Outro na fantasia inconsciente. Assim, a gratuidade pode se tornar um veículo de gozo, caso não seja simbolizada a existência de um outro tipo de ganho possível. Para o paciente, o valor do conhecimento sobre seu modo de gozo.

Para o analista em formação, uma oportunidade de aprender algo que desconhecia. Para o supervisor, uma nova investigação e o crescimento de sua pesquisa.

Rebeca Espinosa Cruz Amaral e Danielle Desirée Souto Maior Cervino escrevem sobre "A.mor.te: Reflexões psicanalíticas sobre o amor e a morte na pandemia". Elas se interrogam acerca do que uma pandemia nos revela sobre as articulações entre o amor e a morte. Por que tememos a morte 
daqueles que amamos? Amor, morte e temor sempre estiveram presentes na clínica e nas elucubrações psicanalíticas, mas se tornaram palavras ainda mais rotineiras em hospitais e consultórios psicanalíticos num contexto pandêmico. Através de uma revisão bibliográfica e da experiência de escuta de pacientes e familiares principalmente num hospital, trazem um estudo sobre as articulações entre amor e morte. $O$ estudo desses temas mostra que eles estão imbricados na psicanálise. Ambos orbitam ao redor da falta e estão relacionadas ao desamparo. Para o psicanalista é essencial saber disso para orientar-se em sua prática.

Andréa Máris Campos Guerra e Mônica Eulália da Silva Januzzi. de forma muito oportuna, nos trazem uma revisão inédita acerca do tema da "Vulnerabilidade social e as modalidades do desamparo em Freud: desamparo estrutural, radical e generalizado". O artigo interroga o termo desamparo em Freud a partir da noção de perigo pulsional, com a finalidade de situar sua especificidade teóricoconceitual, enquanto paradigma para estabelecer um diálogo com o campo das disciplinas sociais. A partir de algumas contribuições da psicanálise lacaniana, a noção de desamparo em Freud, enquanto perigo pulsional, é colocada à prova a partir de três modalizações do termo extraídas das citações encontradas na obra freudiana, isto é: desamparo estrutural, radical e generalizado. A análise dos termos se deu a partir da proposta de análise estrutural de Lacan na distinção entre sentido e significação. Avalio este artigo como muito original. Suas autoras propõem que o desamparo é uma importante ferramenta para o diálogo interdisciplinar entre a psicanálise e as teorias sociológicas pois é o paradigma da vulnerabilidade em psicanálise. E nada mais atual do que distinguir o desamparo estrutural, radical e generalizado - em jogo na concepção psicanalítica de vulnerabilidade, em tempos de pandemia. É fundamental para distinguir os diferentes níveis éticos de responsabilidade diante dela: o político (governos), o científico (estado da ciência) e o social/individual. De que outro modo abordar as reações emocionais diante da pandemia?

O artigo de Virgínia Célia Carvalho da Silva intitulado "Perspectivas clínicas do supereu: desdobramentos desse imperativo categórico no tratamento psicanalítico", parece ter sido cuidadosamente selecionado para suceder a reflexão sobre a vulnerabilidade. A autora apresenta uma revisão do conceito de supereu sob seu aspecto clínico. Este se desdobra em três dimensões: a primeira, que diz respeito às suas manifestações sintomáticas que frequentemente aparecem na demanda inicial de análise. A segunda, que inclui o analista como depositário da exigência superegoica. E a terceira, que leva em conta o final da análise e os destinos do supereu. Destaca-se, nesse texto, o conceito em sua vertente pulsional de exigência real de satisfação. Este trabalho tem o mérito de destacar a dimensão que ultrapassa a dimensão simbólica como instância herdeira do Édipo que promove a interiorização da lei. Em alguns trabalhos, a importância do simbólico chega a desconsiderar a dimensão do real. Acredito que a incidência da dimensão de gozo do supereu é um instrumento indispensável à compreensão das respostas dos sujeitos ao desamparo provocado pela 
pandemia. Como encarar as reações de políticos, médicos assistentes, epidemiologistas, profissionais de saúde e da população em geral à pandemia?

Anderson de Souza Sant'Anna, muito oportunamente, traz formulações em torno do fenômeno da liderança na contemporaneidade. Destaca a dimensão transferencial num espaço transicional. 0 que isto tem a ver com a pandemia? Essencialmente a problematização da liderança numa revista de psicanálise deveria nos servir para reintroduzir a dimensão do Outro na gestão desta catástrofe. Que líderes estiveram à altura do desafio? Em que consiste o exercício da liderança nesta contemporaneidade, quando muitos analistas declaram que "o Outro não existe"?

Estudos contemporâneos em torno da noção de liderança relacional ressaltam: a importância do contexto sobre o valor de tipos psicológicos, traços, competências, condutas e comportamentos pessoais; a compreensão da microfísica das relações de poder, das relações transferenciais que articulam a dimensão intrapsíquicas às relações intersubjetivas. Visa-se, desse modo, desvelar em que extensão as preferências psicológicas, estilos e abordagens de liderança associam-se à construção e sustentação de contextos capacitantes ou espaços transicionais. Relativizando o valor de perfis psicológicos e competências prévias, o artigo promove a importância da dimensão inter e intraorganizacional, na transição para a chamada "Quarta Revolução Industrial" ou "Sociedade 4.0".

Eu concluí da leitura deste artigo que já estamos na "época da psicanálise". Em lugar de esperarmos do governo, dos políticos ou das instituições a liderança em situações de crise, é preciso que uma ética do desejo e da responsabilidade pelo real nos orientem em direção a uma nova maneira de estar no mundo.

Susana Sabba nos recorda que a crise na saúde provocada por esta pandemia não é um real inédito, uma catástrofe nunca experimentada. Ela vai em busca da experiência de Freud e de seus contemporâneos durante a gripe espanhola para lembrar a coincidência temporal entre esta outra tragédia e o nascimento do conceito de pulsão de morte. Para ela, fica a pergunta: será que esta epidemia pode afetar o desejo de viver daqueles que sobreviverem? Quem será mais afetado? Os idosos, em quem o envelhecimento já instaurou uma lenta despedida do desejo de viver, extrairão da experiência da pandemia, um novo reconhecimento do valor da vida? Um novo despertar? 
Citação/Citation: Coelho dos Santos, T. (mai. 2020 a out. 2020). Memórias de uma experiencia amarga: a pandemia de COVID-19. Revista aSEPHallus de Orientação Lacaniana, 15(30), 01-05. Disponível em www.isepol.com/asephallus. Doi: 10.17852/1809-709x.2020v15n30p01-05

Editor do artigo: Tania Coelho dos Santos.

Recebido/Received: 04/03/2020 / 03/04/2020.

Aceito/Accepted: 04/20/2020 / 20/04/2020.

Copyright: (C) 2019 Associação Núcleo Sephora de Pesquisa sobre o moderno e o contemporâneo. Este é um artigo de livre acesso, que permite uso irrestrito, distribuição e reprodução em qualquer meio, desde que o autor e a fonte sejam citados/This is an open-access article, which permites unrestricted use, distribution, and reproduction in any medium, provided the author and source are credited. 